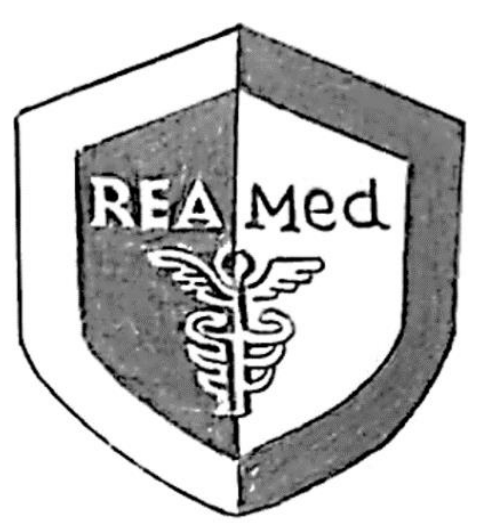

\section{Acervo Médico: uma revista científica que nasceu com propósito}

\author{
Acervo Médico: a scientific journal that was born with purpose
}

Acervo Médico: una revista científica que nació con propósito

D. Andreazzi Duarte ${ }^{1,2 \star}$, Renan Rosa Fiorentini ${ }^{2}$, Paulo Henrique Costa Pimentel $^{2}$, Maisa Cristina Bossi Chaves $^{2}$, Francieli Carolini Pasqualetto ${ }^{1}$.

\title{
RESUMO
}

"Nós não publicamos apenas textos acadêmicos, nós disseminamos conteúdo científico com propósito, para um mundo com mais conhecimento e em constante evolução". Partindo desse conceito, a Revista Eletrônica Acervo Médico (REAMed) foi criada. Ela nasce pela necessidade de novos veículos de publicação de qualidade, objetivando grande missão no cenário científico para o fortalecimento de práticas editoriais baseada em valores e virtudes como: ética, imparcialidade, integridade, confiança e comprometimento com a sociedade, princípio estes que fazem parte da nossa doutrina. Neste editorial contamos um pouco sobre a filosofia Acervo+, mostramos o impacto das nossas publicações e relatamos sobre a nossa luta diária pela disseminação de ciência. Esperamos que aproveitem a leitura e que o conteúdo seja inspirador a todos.

Palavras-chave: Acervo+, Periódico científico, Publicações.

\begin{abstract}
"We don't just publish academic papers, we disseminate scientific content with purpose, for a world with more knowledge and in constant evolution". Based on this concept, the Revista Eletrônica Acervo Médico (REAMed) was created. It born by the need for a new scientific publication with quality, aim a big mission in the scenery of science to strengthening of editorial practices based on values and virtues, such as: ethic, impartiality, integrity, trust and commitment to society, principles that are part of our doctrin. In this editorial we tell a little about the Acervo+ philosophy, show the impact of our publications and show about our daily struggle for the dissemination of science. We hope you take advantage of the reading and that the content will inspire everyone.
\end{abstract}

Keywords: Acervo+, Scientific journal, Publications.

\section{RESUMÉN}

"No solo publicamos artículos académicos, difundimos contenidos científicos con propósito, por un mundo con más conocimiento y en constante evolución". A partir de este concepto se creó la Revista Eletrônica Acervo Médico (REAMed). Nace por la necesidad de una nueva publicación científica con calidad, apunta una gran misión en el escenario de la ciencia al fortalecimiento de prácticas editoriales basadas en valores y virtudes, tales como: ética, imparcialidad, integridad, confianza y compromiso con la sociedad, principios que son parte de nuestra doctrina. En esta editorial contamos un poco sobre la filosofía Acervo +, mostramos el impacto de nuestras publicaciones y mostramos nuestra lucha diaria por la divulgación de la ciencia. Esperamos que aproveches la lectura y que el contenido inspire a todos.

Palabras clave: Acervo+, Revista científica, Publicaciones.

1 Editorial Process Lab (EPL), Acervo+, Brasil. *Contato: @dr.andreazziduarte

2 Editora Acervo+, Brasil. 


\section{NOSSA FILOSOFIA}

A palavra acervo vem do latim acervus e possui vários significados dependendo do contexto que ela é usada. No âmbito pessoal significa abundância, grande quantidade, na visão jurídica se refere a herança, já o olhar social ela é definida por um conjunto de patrimônios de uma nação. Quando tudo começou, a escolha do nome Acervo+ se deu pensando nessa etimologia, pois não haveria nenhuma outra palavra para representar tamanho propósito que foi arquitetado a alguns anos atrás e hoje é um uma abundante fonte de conhecimento e um patrimônio científico e intelectual que, ao longo do tempo, deixa heranças inestimáveis para a sociedade.

Em toda a nossa trajetória, desenvolvemos projetos que mudaram o cenário social, científico e econômico do país, transformando pessoas em protagonistas da sua própria história. Pensamos sempre na evolução dos autores, parceiros e colaboradores, com o viés no desenvolvimento humano em cada atitude. Desde o primeiro contato até a entrega do certificado de publicação temos o compromisso com o foco em 4 pilares: 1) respeito com os autores; 2) valorização do conteúdo; 3) transparência nas avaliações; e por último, 3) uma ciência para todos.

Levamos nossa paixão, entusiasmo e conhecimento para tudo que construímos. Por isso, mantemos uma cultura de trabalho baseada em uma constante evolução e buscamos sempre fazer o melhor! Nosso trabalho não termina quando entregamos a publicação, é ali, que ele realmente começa, quanto os autores passam a ter algo $\mathrm{A}+,_{+}$com a nossa cara e com a nossa alma!

\section{"Quando a missão encontra um propósito maior, ela se perpetua por toda a história" [Inspiraçōes].}

Para tal, carregamos três valores essenciais para o sucesso de nossas publicações e de nossos autores: Inovação, Qualidade e Honestidade. Através destes três conceitos, em sintonia, durante todos os nossos processos editoriais, garantimos uma avaliação justa, correta, que garanta os princípios éticos, morais e científicos para assegurar que somente conteúdo de qualidade, que traga conhecimento verdadeiro, seja publicado.

\section{IMPACTO CIENTÍFICO}

Há mais de 10 anos estamos nos reinventando e inovando para agregar profissionalismo às nossas publicações e, hoje, a Acervo+ é uma das bases científicas mais completas do Brasil, prezando sempre pela qualidade e integridade. Com diversas revistas e milhares de artigos publicados em parceria com grupos de pesquisa espalhados por todo canto, conseguimos impactar leitores de todos os estados do Brasil, além de diversos países do exterior. São milhares de acessos diários ao site oficial acervomais.com, pessoas que vem em busca de conhecimento científico gratuito e certificado pela Acervo+.

Os eventos da Acervo+ tornaram-se um sucesso, reunindo autores que almejam a disseminação da ciência e do conhecimento. Realizados online, com publicação gratuita e totalmente acessíveis, com transmissão em Linguagem Brasileira de Sinais (LIBRAS), os eventos estão se tornando referência no mundo acadêmico, conquistando grande quantidade de autores de resumos e de participantes.

Através dos nossos podcasts, uma iniciativa inédita, os artigos e resumos dos anais de eventos são apresentados de forma oral por meio de 5 plataformas de podcast ao redor do mundo, garantindo acessibilidade e inovando na forma de disseminar a ciência. Somente na Feira Acadêmica de 2021 foram cerca de 50 apresentações orais em podcast e outras 30 apresentações nos três dias de evento ao vivo.

Também passamos a investir na divulgação da ciência por meio das redes sociais, através do Instagram, possibilitando a disseminação da informação científica, mesmo aos que não possuem o hábito de consultar periódicos com frequência. Tencionamos seguir inovando nas formas de informar a sociedade. Nossas revistas eletrônicas, sendo totalmente digitais, não geram impactos ambientais com impressões em papel. 


\section{ATENDENDO UMA DEMANDA SOCIAL}

A ciência todos os dias carece de conteúdo que informe, esclareça e dissemine informações verídicas com confiabilidade em nosso meio acadêmico. A pandemia de Covid-19 tem sido um dos maiores exemplos disso. Ficou evidente para toda a sociedade da importância da ciência e de como uma informação correta é crucial para a comunidade científica e a sociedade em geral. Nesse âmbito, nos empenhamos para transformar vidas e evoluir junto aos nossos autores e da ciência. E esse é o intuito do mais novo periódico da Acervo+ Index base, a Revista Eletrônica Acervo Médico (REAMed).

A revista nasce para proporcionar a comunidade científica uma publicação com a maestria de uma base científica consolidada para que os seus artigos sejam um referencial de qualidade e destaque, repercutindo em um currículo altamente profissional aos autores e com impacto garantido. Esses diferenciais são confirmados pelos diversos relatos que recebemos diariamente de nossos autores e que impulsionam o Time Acervo+ a seguir neste caminho pela disseminação científica.

Somente a divulgação de conteúdo científico acessível e correto pode levar a evolução dos saberes, para que possamos ter como consequência o desenvolvimento duradouro da ciência e das novas e notáveis descobertas. Por isso, é de suma importância que os periódicos estejam atentos as novas necessidades dos seus processos editoriais, além da qualidade dos pareceres, que saiba elencar o material científico e distinguir daquilo que não segue as diretrizes mínimas para um conteúdo de qualidade.

\section{NOSSA LUTA PELA CIÊNCIA}

Seguiremos lutando pela democratização da ciência, como estamos fazendo nos últimos 10 anos, de forma autônoma e independente, sem investimentos públicos, avaliando e orientando de forma gratuita antes de qualquer cobrança. Estimamos que a Revista Eletrônica Acervo Médico seja mais um capítulo da Acervo+ na construção da ciência acessível, jamais deixando de lado o que consideramos valores ímpares: ética, imparcialidade, integridade, confiança, comprometimento, entre tantas coisas.

A publicação de cada artigo é um momento extraordinário para nossa equipe. E a Revista Eletrônica Acervo Médico prosseguirá com os objetivos da Acervo+ (assim como todas as revistas que compõem nossa base científica): atuando como veículos de divulgação científica, impulsionando e facilitando o desenvolvimento acadêmico e profissional, a educação continuada e permanente e proporcionando materiais técnico-científicos aos pesquisadores.

Sendo assim, este editorial configura-se também um convite para todos que desejarem participar deste movimento, contribuindo para a ciência médica e passando a fazer parte de uma base científica conceituada e destacada pela qualidade e respeito com os princípios da ética e da ciência. Contamos com vocês para construir uma ciência com inovação, qualidade e honestidade.

"Nós não publicamos apenas textos acadêmicos, nós disseminamos conteúdo científico com propósito, para um mundo com mais conhecimento e em constante evolução".

Dr. Andreazzi Duarte.

Acervot e você, juntos pela ciêncía!

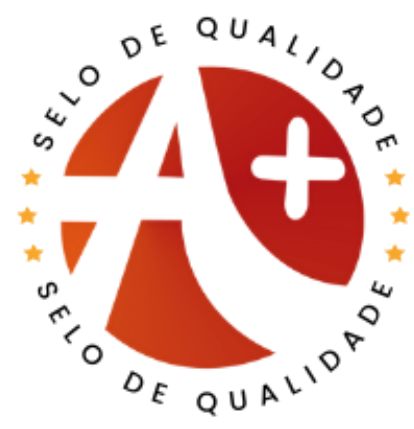

